\title{
Neuroanatomical correlates of psychosis in temporal lobe epilepsy: voxel-based morphometry study
}

\author{
Frederick Sundram, Mary Cannon, Colin P. Doherty, Gareth J. Barker, Mary Fitzsimons, \\ Norman Delanty and David Cotter
}

\section{Background}

Temporal lobe epilepsy is associated with a significant risk of psychosis but there are only limited studies investigating the underlying neurobiology.

\section{Aims}

To characterise neuroanatomical changes in temporal lobe epilepsy and comorbid psychosis.

\section{Method}

The study population comprised all individuals with temporal lobe epilepsy on the epilepsy database at the National Centre for Epilepsy and Epilepsy Neurosurgery in Ireland (Beaumont Hospital) between 2002 and 2006. Ten people with temporal lobe epilepsy with psychosis were matched for age, gender, handedness, epilepsy duration, seizure laterality, severity of epilepsy and anti-epileptic medication with ten comparison participants with temporal lobe epilepsy only. Participants received a magnetic resonance imaging scan and voxel-based morphometry analyses were applied to grey and white matter anatomy.

\section{Results}

Significant grey matter reduction was found bilaterally in those with temporal lobe epilepsy with psychosis in the temporal lobes in the inferior, middle and superior temporal gyri and fusiform gyri, and unilaterally in the left parahippocampal gyrus and hippocampus. Significant extratemporal grey matter reduction was found bilaterally in the insula, cerebellum, caudate nuclei and in the right cingulum and left inferior parietal lobule. Significant white matter reduction in those with temporal lobe epilepsy with psychosis was found bilaterally in the hippocampus, parahippocampal/fusiform gyri, middle/inferior temporal gyri, cingulum, corpus callosum, posterior thalamic radiation, anterior limb of internal capsule and white matter fibres from the caudate nuclei, and unilaterally in the left lingual gyrus and right midbrain and superior temporal gyrus.

\section{Conclusions}

Significant grey and white matter deficits occur in temporal lobe epilepsy with psychosis. These encompass the medial temporal lobe structures but also extend to lateral temporal and extratemporal regions. Some of these deficits overlap with those found in schizophrenia.

\section{Declaration of interest}

C.P.D. is on the advisory boards for Eisai and UCB Pharma and has received educational funding from Janssen-Cilag. G.J.B. has received honoraria for lecturing for GE Healthcare.
Epilepsy is one of the most common and debilitating neurological disorders, with a prevalence of 5-10 per 1000 population. ${ }^{1}$ The lifetime risk of psychiatric disorder in temporal lobe epilepsy is estimated to be as high as $60 \% .^{2}$ Specifically, temporal lobe epilepsy carries a substantial risk of psychosis at a prevalence rate of $2-7 \%$, which is several times greater than that seen in the general population. ${ }^{3-7}$ Although temporal lobe epilepsy represents one of the highest known risk factors for the development of psychosis, very little is known about the neurobiology of temporal lobe epilepsy and associated psychosis.

The relationship between the temporal lobe and psychosis was first reported in 1963 by Slater and colleagues ${ }^{8}$ and some forms of temporal lobe epilepsy with psychosis have been noted to closely resemble schizophrenia. ${ }^{9}$ Temporal lobe epilepsy with psychosis has also been postulated to arise from abnormalities in fetal brain development, and to represent a model or 'mock-up' of schizophrenia. ${ }^{10}$ It is recognised that these conditions possibly share common genetic or environmental causes, ${ }^{11}$ and recently the mean interval between the onset of epilepsy and that of psychosis has been reported to be approximately 14.4 years. ${ }^{12}$

Temporal lobe epilepsy has been associated with a variety of environmental insults such as birth injury, febrile convulsions, head trauma or central nervous system infection and where associated with genetic vulnerability may lead to acquired changes in brain anatomy. ${ }^{13}$ Up until the 1980 s such changes in neuroanatomy were assessed through post-mortem neuropathological studies; however, with the advent of magnetic resonance imaging (MRI), most of such changes have been readily imaged in vivo and have been quantified using manual and computerised statistical methods. These methods provide an opportunity to improve our understanding of the pathogenesis of not only the psychosis associated with temporal lobe epilepsy but the causative mechanisms of psychosis in general.

So far, there have only been a limited number of MRI studies that have assessed regional volumetric differences in people with temporal lobe epilepsy and psychosis specifically. Three previous studies used manual region of interest (ROI) volumetry to compare participants with temporal lobe epilepsy only versus those with temporal lobe epilepsy with psychosis. Findings have included reduction of volume in the temporal, frontal and parietal lobes and superior temporal gyrus and left hippocampus grey matter volumes and also bilateral amygdala enlargement. ${ }^{14-16}$ Overall, however, the findings from manual ROI studies have not been consistent. A more recent study attempted to overcome the difficulties of reproducibility introduced by manual volumetry by using automated whole brain voxel-based morphometry (VBM). This study limited the assessment to grey matter and observed no cortical differences between groups. ${ }^{17}$ As this was not consistent with neuroimaging findings in schizophrenia, ${ }^{18,19}$ the authors suggested that temporal lobe epilepsy with psychosis may be a distinct entity to schizophrenia. 
As reports thus far have inconsistently reported neuropathology in several brain regions and the application of ROI volumetry to investigate structural abnormalities in people with temporal lobe epilepsy is difficult to reproduce and time consuming, ${ }^{20}$ we undertook the first VBM study of temporal lobe epilepsy with psychosis using unbiased, automated, quantitative voxel-based techniques to encompass both grey and white matter measures at a whole brain level. As this is the first study of its kind, the VBM approach was considered the most appropriate because it allows a hypothesis-free survey of the entire brain. This may subsequently permit hypotheses generation and areas to be investigated in future projects or the further application of advanced neuroimaging techniques.

Given the previous findings using manual volumetry, in the current study we hypothesised that individuals with temporal lobe epilepsy with psychosis when compared to those with temporal lobe epilepsy without psychiatric disorder would demonstrate: reduction in total brain and grey and white matter content; grey and white matter reduction in the temporal lobe; and structural differences that overlap with those found in schizophrenia.

\section{Method}

\section{Study population}

Our study was carried out at the National Centre for Epilepsy and Epilepsy Neurosurgery, Beaumont Hospital, Dublin, Ireland. We used a retrospective approach to identify people with temporal lobe epilepsy and ethics approval was provided by the Beaumont Hospital Medical Research Ethics Committee (reference number: 04/55).

Our study population included all individuals on our hospital's research and clinical epilepsy database. The database represents ongoing efforts to develop a register of patients with epilepsy within Ireland (more details available at www. epilepsyprogramme.ie). We assessed individuals on the database attending the in-patient and out-patient neurology service at Beaumont Hospital between 2002 and $2006(n=860)$. As our centre has an epilepsy surgery programme where appropriate candidates receive presurgical evaluation, the epilepsy population under study represents a combination of medically managed and those with medically intractable or surgically remediable epilepsies.

Two epileptologists (C.P.D. and N.D.) examined a combination of seizure semiology, electroencephalogram (EEG), video-EEG telemetry and neuroimaging data. A diagnosis of epilepsy was based on the International League Against Epilepsy classification system, ${ }^{21}$ and our study participants had already been examined in prior studies ${ }^{22-24}$ and had consented to further assessment. The neurology service routinely refers people with epilepsy and suspected psychiatric disorder for neuropsychiatric assessment and these assessments are comprehensive, documented in detail and include diagnoses/neuropsychiatric formulation based on the ICD-10 classification system. ${ }^{25}$

Exclusion criteria for participation were a clinically detectable medical disorder known to affect gross brain structure (e.g. tumour, haemorrhage), pervasive developmental disorders (e.g. autism-spectrum disorder), individuals with an extratemporal epileptic focus, generalised or unclassified seizures, an IQ $<70$ on WAIS-R, ${ }^{26}$ age $<18$ years, previous neurosurgery, non-righthandedness and individuals with contraindications to MRI scanning or no suitable MRI scan. As the software on our MRI scanner was upgraded in 2002, people scanned prior to this date were excluded to ensure homogeneity of scan parameters.

\section{Participants with temporal lobe epilepsy with psychosis}

The clinical syndrome we were interested in was defined as complex partial seizures with clinical findings and investigations
(EEG and MRI) compatible with temporal lobe epilepsy. Further, the presence of delusions and/or hallucinations resulting in an ICD-10 diagnosis for psychosis was essential. Acute confusional states or depressive symptomatology alone were not deemed sufficient. Individuals with a drug-induced psychosis or episodes of psychosis provoked by excessive alcohol consumption or those representing complex partial status were also excluded.

Of the 860 individuals with epilepsy identified on the database, 280 had a diagnosis of temporal lobe epilepsy of whom 26 had been diagnosed with psychosis by the neuropsychiatric service. However, of these 26 with temporal lobe epilepsy with psychosis, 7 had previous neurosurgery for medically intractable seizures, 2 had an existing tumour, 1 was left-handed, 4 had an MRI scan at another institution either in Ireland or abroad and 2 had incomplete MRI scans. Consequently, ten individuals with temporal lobe epilepsy with psychosis (the epilepsy+psychosis group) were considered suitable for participation in our study (Fig.1).

\section{Comparison group}

Using the Beaumont Hospital research and clinical epilepsy database, each epilepsy+psychosis participant included in the study was then matched for age (s.d. $=5$ years), gender, handedness, epilepsy duration, seizure laterality, severity of epilepsy and anti-epileptic medication with an individual with temporal lobe epilepsy but no psychosis who was attending the same neurology service. None of the comparison group (epilepsy-only group) had a lifetime history of prior psychosis and all were free of comorbid psychiatric disorder in the preceding year.

\section{Chart review}

Chart reviews were conducted for both the epilepsy+ psychosis group and epilepsy-only group. The clinical assessments of the

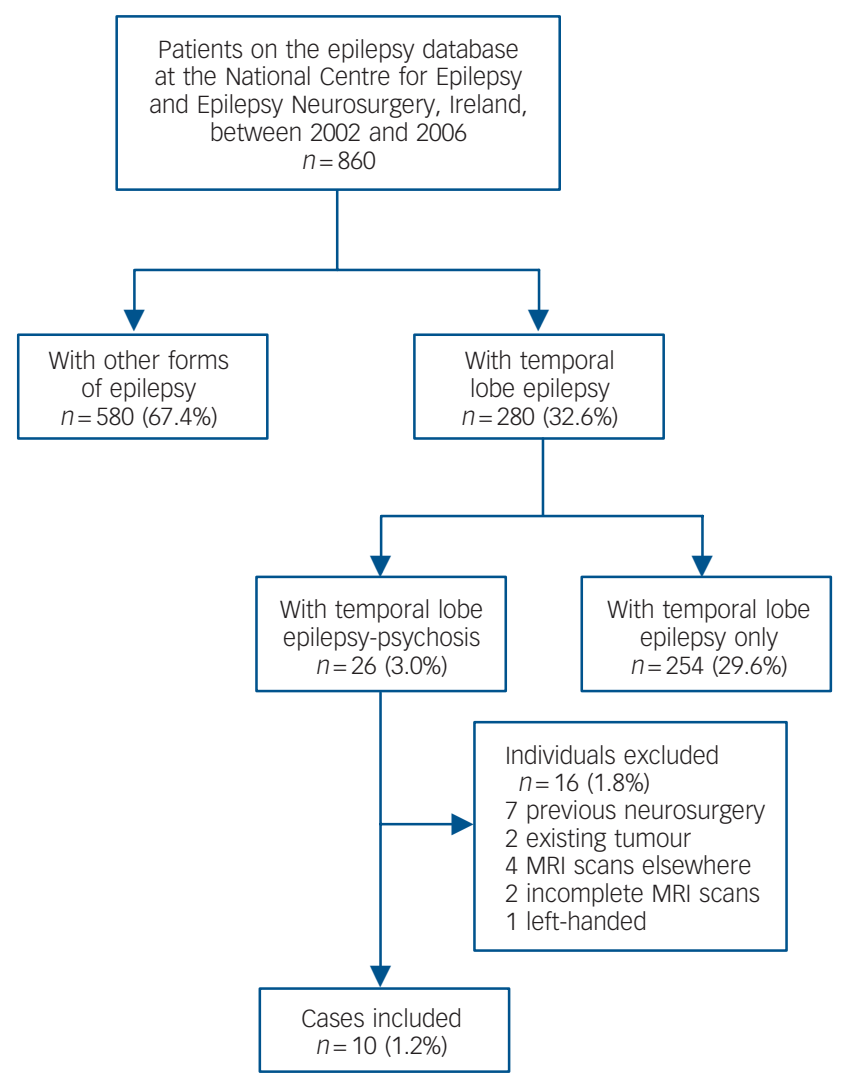

Fig. 1 Summary of participant selection. MRI, magnetic resonance imaging. 
epilepsy + psychosis group completed by the specialised neuropsychiatry service were objectively assessed using the Operational Criteria Checklist for Psychotic Illness (OPCRIT). ${ }^{27}$ This was used as it offers a polydiagnostic classification system that yields operationally defined psychiatric diagnoses with good reliability. ${ }^{28}$

All the epilepsy+psychosis group had to fulfil ICD-10 criteria for psychotic disorder that encompassed schizophrenia, persistent delusional disorder or other non-organic psychotic disorder; affective psychoses were excluded. With regard to timing of psychoses relative to seizure events, post-ictal psychoses were included where MRI and neuropsychiatric assessments were performed within a week of psychotic episodes, whereas inter-ictal psychoses were included where the same assessments were completed within a month of commencement of psychosis in the absence of antecedent seizure activity. Neither the epilepsy+ psychosis group nor the epilepsy-only group had features of intellectual disability, non-epileptic seizures or history of poor adherence with their anti-epileptic medication. For a summary of participant characteristics see Tables 1 and 2.

\begin{tabular}{|c|c|c|c|}
\hline & Epilepsy+psychosis group $(n=10)$ & Epilepsy-only group $(n=10)$ & $P^{a}$ \\
\hline Age: years, mean (s.d.) & $35(5.2)$ & $33(6.1)$ & 0.36 \\
\hline Male/female, $n$ & $7 / 3$ & $7 / 3$ & \\
\hline Right-handed, $n$ & 10 & 10 & \\
\hline Age at diagnosis of epilepsy, mean (s.d.) & $12(11.0)$ & $16(8.2)$ & 0.41 \\
\hline Epilepsy duration: years, mean (s.d.) & $23(12.4)$ & $17(8.6)$ & 0.20 \\
\hline \multicolumn{4}{|l|}{ Site of epileptic focus } \\
\hline Right-sided & 6 & 6 & \\
\hline Left-sided & 4 & 4 & \\
\hline \multicolumn{4}{|l|}{ Lesional $v$. non-lesional } \\
\hline $\begin{array}{l}\text { Mesial temporal sclerosis } \\
\text { Non-lesional }\end{array}$ & $\begin{array}{l}6 \text { (4 right and } 2 \text { left) } \\
4\end{array}$ & $\begin{array}{l}5 \text { (4 right and } 1 \text { left) } \\
5\end{array}$ & \\
\hline Age at first psychotic event: years, mean (s.d.) & $30(5.6)$ & N/A & \\
\hline Duration of epilepsy at time of first psychotic event: years, mean (s.d.) & $18(9.9)$ & N/A & \\
\hline
\end{tabular}

\begin{tabular}{|c|c|c|c|c|c|c|c|c|c|c|}
\hline \multirow[b]{2}{*}{ Participant } & \multirow{2}{*}{$\begin{array}{l}\text { Timing of psychosis } \\
\text { relative to seizure } \\
\text { event }\end{array}$} & \multirow{2}{*}{$\begin{array}{l}\text { Antipsychotic } \\
\text { medication }\end{array}$} & \multirow[b]{2}{*}{$\begin{array}{l}\text { Daily } \\
\text { dosage }\end{array}$} & \multicolumn{5}{|c|}{ Epilepsy clinical data } & \multirow{2}{*}{$\begin{array}{l}\text { Epilepsy+psychosis } \\
\text { group anti- } \\
\text { epileptic medication }\end{array}$} & \multirow{2}{*}{$\begin{array}{l}\text { Matched epilepsy-only } \\
\text { group anti- } \\
\text { epileptic medication }\end{array}$} \\
\hline & & & & $\begin{array}{l}\text { Seizure } \\
\text { frequency }\end{array}$ & Aura & CPS & $S G$ & Refract & & \\
\hline 1 & Inter-ictal & Haloperidol & $20 \mathrm{mg}$ & 1/week & Y & Y & N & N & Levetiracetam & $\begin{array}{l}\text { Levetiracetam } \\
\text { Oxcarbazepine } \\
\text { Lamotrigine }\end{array}$ \\
\hline 2 & Post-ictal & Amisulpride & $800 \mathrm{mg}$ & $1 /$ month & N & Y & $N$ & N & $\begin{array}{l}\text { Valproate } \\
\text { Levetiracetam }\end{array}$ & Valproate \\
\hline 3 & Inter-ictal & Risperidone & $6 \mathrm{mg}$ & 1/week & N & Y & $N$ & N & $\begin{array}{l}\text { Levetiracetam } \\
\text { Phenytoin } \\
\text { Valproate }\end{array}$ & $\begin{array}{l}\text { Levetiracetam } \\
\text { Carbamazepine } \\
\text { Topiramate }\end{array}$ \\
\hline 4 & Inter-ictal & Haloperidol & $2 \mathrm{mg}$ & $2 /$ day & Y & Y & Y & Y & $\begin{array}{l}\text { Carbamazepine } \\
\text { Levetiracetam } \\
\text { Gabapentin }\end{array}$ & Carbamazepine \\
\hline 5 & Post-ictal & Olanzapine & $5 \mathrm{mg}$ & $1 /$ day & Y & Y & Y & Y & $\begin{array}{l}\text { Levetiracetam } \\
\text { Valproate } \\
\text { Lamotrigine }\end{array}$ & $\begin{array}{l}\text { Levetiracetam } \\
\text { Valproate } \\
\text { Oxcarbazepine }\end{array}$ \\
\hline 6 & Post-ictal & $\begin{array}{l}\text { Thioridazine/ } \\
\text { Olanzapine }\end{array}$ & $\begin{array}{l}400 \mathrm{mg} / \\
30 \mathrm{mg}\end{array}$ & $1 /$ day & Y & Y & Y & Y & $\begin{array}{l}\text { Oxcarbazepine } \\
\text { Topiramate }\end{array}$ & $\begin{array}{l}\text { Oxcarbazepine } \\
\text { Clobazam }\end{array}$ \\
\hline 7 & Post-ictal & $\begin{array}{l}\text { Haloperidol/ } \\
\text { Olanzapine }\end{array}$ & $\begin{array}{l}5 \mathrm{mg} / \\
20 \mathrm{mg}\end{array}$ & $1 / 2$ weeks & Y & Y & $\mathrm{N}$ & N & $\begin{array}{l}\text { Carbamazepine } \\
\text { Valproate } \\
\text { Vigabatrin }\end{array}$ & Carbamazepine \\
\hline 8 & Post-ictal & Olanzapine & $20 \mathrm{mg}$ & 3-4/week & Y & Y & Y & Y & $\begin{array}{l}\text { Topiramate } \\
\text { Oxcarbazepine }\end{array}$ & $\begin{array}{l}\text { Topiramate } \\
\text { Carbamazepine } \\
\text { Clobazam } \\
\text { Phenobarbitone }\end{array}$ \\
\hline 9 & Inter-ictal & Olanzapine & $20 \mathrm{mg}$ & $1 /$ month & Y & Y & $N$ & N & $\begin{array}{l}\text { Carbamazepine } \\
\text { Valproate }\end{array}$ & $\begin{array}{l}\text { Carbamazepine } \\
\text { Levetiracetam } \\
\text { Vigabatrin }\end{array}$ \\
\hline 10 & Inter-ictal & Olanzapine & $12.5 \mathrm{mg}$ & 2-3/week & Y & Y & Y & Y & $\begin{array}{l}\text { Carbamazepine } \\
\text { Phenobarbitone } \\
\text { Levetiracetam }\end{array}$ & $\begin{array}{l}\text { Carbamazepine } \\
\text { Lamotrigine }\end{array}$ \\
\hline
\end{tabular}




\section{MRI brain image acquisition}

All participants had a volumetric spoiled gradient recalled (SPGR) acquisition in the steady-state MRI brain scan at Beaumont Hospital using a $1.5 \mathrm{~T}$ scanner (GE Signa Systems, Paris). Coronal thin-cut $1.5 \mathrm{~mm}$ slices were obtained via a three-dimensional (3D)-volume gradient echo-pulse sequence that was radiofrequency spoiled. A sagittal localiser was first acquired and the volume of interest was then arranged to include the whole brain. The 3D-SPGR sequence was acquired over a period of $14 \mathrm{~min}$ with the following MRI parameters: repetition time $(\mathrm{TR})=35 \mathrm{~ms}$, echo time $(\mathrm{TE})=15 \mathrm{~ms}$, readout bandwidth of $16 \mathrm{kHz}$ and excitation flip angle of $35^{\circ}$. The data were collected with an in-plane image matrix of $256 \times 256$ pixels over a field of view (FOV) of $24 \times 24 \mathrm{~cm}$, leading to a voxel size of $0.09375 \times 0.09375 \mathrm{~cm}$. In total, 128 partitions were collected, of which 4 were discarded during reconstruction to minimise wraparound artefacts, resulting in a final $1241.5 \mathrm{~mm}$ slices covering a field of view of $18.6 \mathrm{~cm}$.

\section{Image analysis}

Investigators were masked to participant group and each scan was checked for movement artefact and corruption prior to inclusion in the image-processing pipeline. In brief we used VBM that offers an unbiased and fully automated whole brain measurement technique that normalises all the images to the same stereotactic space and subsequently segments, modulates and smoothes images (as described in more detail below); a statistical analysis is finally performed on the smoothed images to localise and make inferences about group differences. ${ }^{29}$ Registration into standard space, segmentation, modulation and smoothing was performed using Statistical Parametric Mapping software (SPM5, Wellcome Department of Imaging Neurosciences, University College London, UK; www.fil.ion.ucl.ac.uk/spm/) within Matlab 7.0 (The MathWorks, Natick, Massachusetts, USA; www.mathworks.com/ products/matlab/) run on UNIX and statistical analyses were applied in the Brain Activation and Morphological Mapping (BAMM; www-bmu.psychiatry.cam.ac.uk/BAMM/index.html) package.

With previous versions of SPM, a set of processing steps commonly known as 'optimised $\mathrm{VBM}^{30}$ was needed to ensure high-quality segmentations. However, the methodology was inherently circular as the registration required an initial tissue classification, and the tissue classification requires an initial registration. In SPM5 both components are integrated into a single model and it also includes correction of the effects of image intensity non-uniformity termed 'the bias field'. ${ }^{31}$ Grey and white matter were extracted from the normalised images and 'modulated' to compensate for the effects of spatial normalisation. This is achieved by multiplying each voxel value by its relative volume before and after warping, in order to compensate for the fact that spatial normalisation expands/contracts some brain regions. ${ }^{31}$ After modulation, the total amount of grey (or white) matter is the same as in the original images. Good and colleagues note that in effect, an analysis of modulated data tests for regional differences in the absolute amount (volume) of grey matter. ${ }^{30}$ The maps so produced are referred to as images of 'grey (or white) matter volume' to distinguish them from the images of 'concentration' or 'density' that result if the modulation stage is omitted. In this study, however, in order to avoid potential confusion with manual volumetry measures such as stereology, we refer to them as 'maps of grey (or white) matter content', or simply 'grey (or white) matter maps'.

Scans need to be smoothed in order to reduce confounds as a result of individual variation in neuroanatomy. Smoothing the data in order to coerce it into the appropriate statistical distribution is also a prerequisite for some analytical approaches, but is not necessary for our non-parametric approach (see below). The degree of smoothing to apply is still a subject of much discussion as different smoothing levels result in varying results. We applied a smoothing filter (Gaussian, $8 \mathrm{~mm}$ full-width at half maximum) as the literature suggests that this would aid the detection of potentially widespread changes in the neocortex and changes in smaller subcortical structures, ${ }^{32}$ between-participant anatomical matching and to improve the signal-to-noise ratio. ${ }^{29,33}$ Additionally, total global, grey matter and white matter volumes were extracted via SPM5 and between-group differences were compared using non-parametric Mann-Whitney $U$-tests. If these volumes were to significantly differ, they are then entered as covariates in between-group analyses. Similarly, characteristics such as epilepsy duration or age are entered as covariates in the analytical model should they significantly differ between groups.

\section{Brain activation and morphological mapping}

As structural brain changes are likely to extend over a number of contiguous voxels, test statistics incorporating spatial information such as 3D cluster mass (the sum of suprathreshold voxel statistics), are generally more powerful than other possible test statistics, which are informed only by data at a single voxel. ${ }^{34}$ Given that no parametric distribution is known for cluster mass, permutation-based testing that is implemented in the BAMM package (a joint development of the Brain Mapping Unit, Department of Psychiatry, University of Cambridge and The Institute of Psychiatry, London, UK) was used to assess statistical significance at both the voxel and cluster levels. ${ }^{34}$

Between-group differences in grey and white matter volume were estimated by fitting an analysis of covariance (ANCOVA) model at each intracerebral voxel in standard space where proportional volume for each tissue class (grey or white matter) was the dependent variable and group classification as the key predictor variable. ${ }^{35}$ Instead of setting a single a priori $P$-value below which we regard findings as significant at the cluster level, we calculated, for a range of $P$-values, the number of clusters that would be expected by chance alone. We started by setting a relatively lenient $P \quad(P \leqslant 0.05)$ to detect voxels putatively demonstrating differences between groups; subsequently, we searched for spatial clusters of such voxels and tested the 'mass' of each cluster (the sum of suprathreshold voxel statistics it comprises) for significance.

We then set the statistical threshold for cluster significance such that the expected number of false positive clusters arising by chance alone would be less than one over the whole imaging volume. As SPM was used initially for segmentation, BAMM yielded coordinates of clusters in Montreal Neurological Institute (MNI) space; MNI coordinates were subsequently converted to Talairach space via a non-linear transformation ${ }^{36}$ (further details can be found at http://imaging.mrc-cbu.cam.ac.uk/imaging/ MniTalairach) and interpreted with the aid of widely accepted atlases. $^{37}$

Our non-parametric or distribution-free hypothesis testing procedure allows us to use cluster-level statistics even if their distribution is non-Gaussian (even after smoothing); further, there is significant evidence in the literature that cluster-level statistics incorporating information about the spatial neighbourhood of each voxel may be more sensitive than voxel test statistics. $^{35,38,39}$ As voxel-level statistics are associated with multiple comparisons and thus increased risk of type I error, cluster-level statistics reduce such error due to the performance of fewer comparisons of several orders of magnitude. ${ }^{35}$ Finally, although variance of the data may differ with brain area, our clusters are evaluated over the whole brain and we also inspected 
the voxel-level maps, in order to check for any gross discrepancies between cluster and voxel level. More details can be found at www-bmu.psychiatry.cam.ac.uk/software/docs/xbamm/.

\section{Results}

\section{Total tissue volumes}

There were no significant differences in median total global, grey or white matter volumes between the groups at the $P=0.05$ level, although there was an approximate reduction of 6,5 and $7 \%$ respectively in these tissue classes in the epilepsy+psychosis group (Table 3).

\section{VBM of grey and white matter content}

We found regional deficits affecting both grey and white matter but these changes were confined to the epilepsy+psychosis group. We found significant regional grey matter reduction unilaterally in the medial temporal lobe structures such as the left parahippocampal gyrus and hippocampus. Deficits also extended to the lateral temporal lobes encompassing the bilateral inferior, middle and superior temporal gyri and fusiform gyri. However, grey matter reduction was not limited to the temporal lobe structures but also extended to extratemporal regions. The most significant extratemporal deficits were distributed bilaterally and included the insula, cerebellum and caudate nuclei, and unilaterally in the right cingulum and left inferior parietal lobule (Fig. 2).

We also found significant regional white matter reduction in the epilepsy+psychosis group. Within the medial temporal lobe, these deficits were distributed bilaterally in the hippocampus and parahippocampal gyrus. White matter deficits were also found in the lateral temporal lobes bilaterally in the middle and inferior temporal gyri and fusiform gyri, whereas unilateral deficits were found in the right superior temporal gyrus. Reduction of white matter extended beyond the boundaries of the temporal lobes and bilaterally involved the cingulum, corpus callosum (genu, splenium and tapetum), anterior limb of internal capsule, posterior thalamic radiation and white matter fibres from the caudate nuclei, whereas unilateral deficits were found in the left lingual gyrus and right midbrain (Fig. 3). Tables 4 and 5 provide a summary of the anatomical locations of grey and white matter deficits.

\section{Discussion}

\section{Main findings}

Although Slater and colleagues ${ }^{8}$ observed the occurrence of schizophrenia-like psychoses in association with epilepsy some 50 years ago, very few MRI studies have been undertaken since then and even fewer have attempted to accurately quantify in vivo the brain changes seen in the psychoses related to temporal lobe epilepsy. In this study we conducted the first ever comparison (at a whole brain level) of grey and white matter tissue classes of a well-matched group of adults with temporal lobe epilepsy with psychosis versus those with temporal lobe epilepsy only, using unbiased automated voxel-based statistical methods. Each participant had a robust diagnosis of temporal lobe epilepsy based on clinical, neuroimaging and electrophysiological criteria. Further, individuals that had been clinically diagnosed with psychosis were then confirmed objectively via a validated polydiagnostic classification system and were subsequently matched with controls that had temporal lobe epilepsy only and were free from psychiatric disorder. The MRI scans were based on a standardised epilepsy brain imaging protocol to ensure homogeneity of scan parameters where the timing of MRI scan acquisition was close to the development of psychosis and therefore we explored the relationship between acute (rather than chronic) psychosis and potential brain changes. We found significant temporal and extratemporal lobe deficits among those with comorbid psychosis.

We found both grey and white matter regional deficits in temporal lobe epilepsy with psychosis compared with temporal lobe epilepsy only where deficits were mainly localised to the temporal lobe. For example, significant grey matter deficits were found in the medial temporal lobes in the left hippocampus and parahippocampal gyrus. These findings are compatible with the neuroanatomical and neuropsychological deficits described in schizophrenia. ${ }^{18,40,41}$ However, we also found evidence of deficits bilaterally in the lateral temporal lobes and in extratemporal regions perhaps suggesting that the psychosis seen in temporal lobe epilepsy is the result of more widespread abnormalities.

Strengthening our argument that psychosis in temporal lobe epilepsy may be a more widely distributed disorder is the finding of grey matter deficits in the cingulum, insula and cerebellum; grey matter reduction in the insula and cingulum have been associated with psychosis ${ }^{35,40}$ and the cerebellum is emerging as an organ not only involved in motor coordination but also in higher cortical functions. Abnormalities in the cerebellum have previously been postulated to result in a 'cognitive dysmetria ${ }^{42}$ characterised by impairments in coordination of the perception, encoding, retrieval and prioritisation of experience and information and may arise from a defect in circuitry connecting the thalamus, frontal cortex and cerebellum. Although cerebellar grey matter deficits have been previously reported in people with temporal lobe epilepsy without comorbid psychiatric disorder, ${ }^{43}$ given that there are reciprocal neural pathways between the hippocampus and cerebellum, the cerebellum in those with psychosis may perhaps be particularly vulnerable to excitotoxic damage as a result of its connectivity with a pathological hippocampus. Currently, cerebellar abnormalities are also recognised to contribute to the development of schizophrenia ${ }^{40,44}$ and although we found evidence of grey matter reduction in the cerebellum, these were not specifically quantified and should be thus considered preliminary.

Pronounced white matter deficits were also found in our study in regions that included the corpus callosum, hippocampi, cingulum and parahippocampal gyri. Impaired intra- and interhemispheric connectivity has been suggested to play a major role in the development of schizophrenia ${ }^{35,45}$ and currently there is strong evidence of widespread altered cortico-cortical and

Table 3 Median total volume of tissue classes in epilepsy+psychosis $v$. epilepsy-only group

\begin{tabular}{|lccc|}
\hline & Epilepsy+psychosis group, median (s.d.) & Epilepsy-only group, median (s.d.) & $P^{\text {a }}$ \\
\hline Total brain volume, $\mathrm{ml}$ & $1142.7(133.8)$ & $1212.1(114.9)$ & 0.07 \\
\hline Total grey matter volume, $\mathrm{ml}$ & $687.5(76.6)$ & $722.6(56.0)$ & 0.08 \\
\hline Total white matter volume, $\mathrm{ml}$ & $455.1(59.5)$ & $490.8(67.6)$ & 0.11 \\
\hline a. All values represent asymptotic significance (2-tailed) Mann-Whitney U-tests. & & & \\
\hline
\end{tabular}




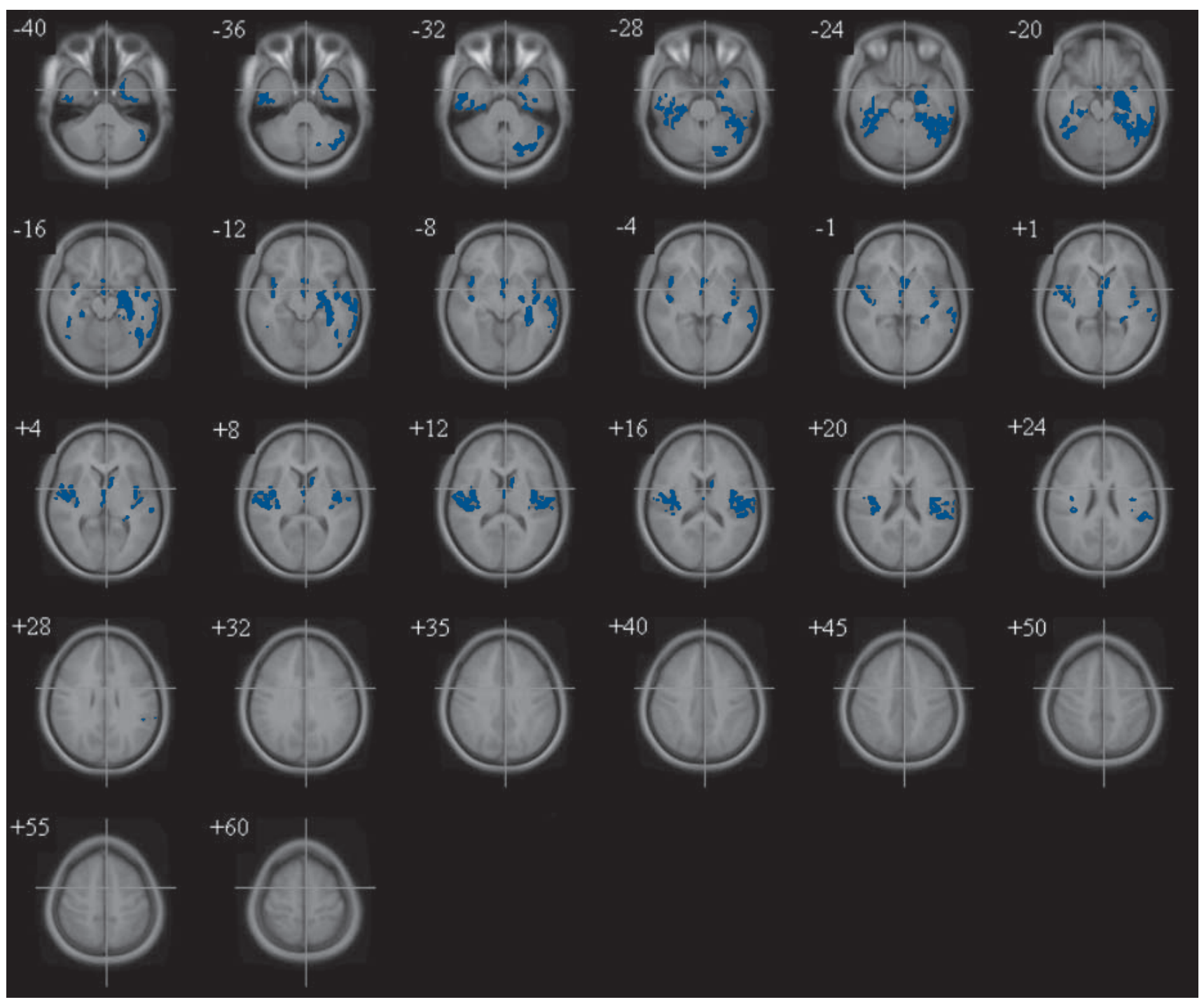

Fig. 2 Ascending transverse sections demonstrating regional grey matter reduction (blue) in participants with temporal lobe epilepsy with psychosis (image is flipped so left is right and right is left).

transcallosal connections between homologous brain regions in schizophrenia. ${ }^{46}$ Abnormalities in such tracts may also contribute to the development of psychosis seen in temporal lobe epilepsy. Given our finding of greater white matter content deficits relative to grey matter in temporal lobe epilepsy with psychosis, assessment of white matter microstructure and connectivity should therefore be considered in future studies using a combination of VBM and advanced neuroimaging techniques such as diffusion tensor imaging as has been applied in other disorders where white matter is preferentially affected. ${ }^{47}$

\section{Findings from other studies}

Although the left temporal lobe has been associated with temporal lobe epilepsy with psychosis in older reports, ${ }^{48}$ the literature is not entirely consistent. ${ }^{49}$ Suboptimal matching may have contributed to this inconsistency. Furthermore, the majority of studies have employed manual volumetric region of interest techniques for example hand-tracing or stereology that may not be easily reproducible. One such manual volumetry study that compared temporal lobe epilepsy, temporal lobe epilepsy with psychosis and schizophrenia with healthy controls via hand-tracing methods reported ventricular enlargement and smaller temporal, frontal and parietal lobes and superior temporal gyrus grey matter volumes in all groups with the most pronounced differences being found in the temporal lobe epilepsy with psychosis group. ${ }^{14}$ Based on their findings, the authors concluded that cortical grey matter deficits in temporal lobe epilepsy with psychosis and schizophrenia predispose to chronic psychosis.

In another manual volumetry study, participants with temporal lobe epilepsy with psychosis were reported to have smaller total brain volumes than either individuals with temporal lobe epilepsy alone or healthy volunteers. No group differences were observed in hippocampal volumes, although bilateral amygdala enlargement of the order of $16-18 \%$ was reported in those with temporal lobe epilepsy with psychosis. ${ }^{15}$ However, as some of the participants with temporal lobe epilepsy only were dysthymic, this may have confounded findings. Hippocampal volume deficit was found in a further manual volumetry study of temporal lobe epilepsy with psychosis relative to healthy controls where the left hippocampus was reported as significantly smaller than the right. ${ }^{16}$

Overall, manual volumetry-based studies of temporal lobe epilepsy with psychosis have not reported consistent findings. Keller and colleagues ${ }^{20}$ argue that there are inherent difficulties 


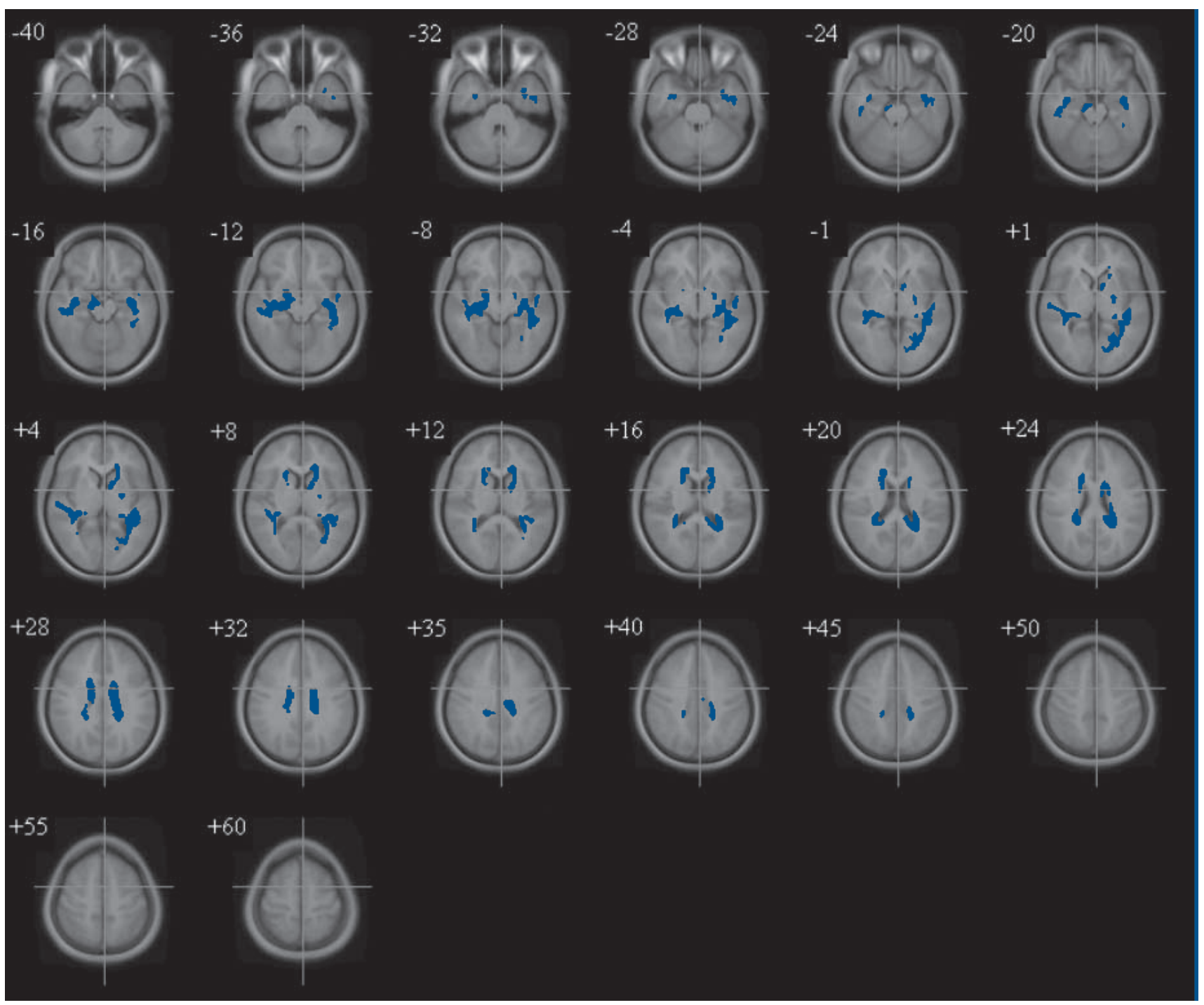

Fig. 3 Ascending transverse sections demonstrating regional white matter reduction (blue) in participants with temporal lobe epilepsy with psychosis. (image is flipped so left is right and right is left).

with manual volumetry (for instance stereology) that may account for such inconsistent evidence. For example, there is subjectivity associated with point counting on MRIs and in judgement of boundaries of structures under investigation (e.g. delineation between hippocampus, white matter and cerebrospinal fluid). These differences in judgement may lead to differing volume estimates between raters. Additionally, the calibration of MRIs with settings such as image brightness may influence the perception of brain tissue contrasts. Despite the inconsistencies reported with manual volumetry, automated techniques have only been applied on a limited basis in temporal lobe epilepsy with psychosis.

In one such automated computerised statistical study, ${ }^{17}$ the authors retrospectively explored cortical grey matter differences between 26 participants with temporal lobe epilepsy with psychosis, 24 with temporal lobe epilepsy only and 20 healthy comparisons. This was the same cohort as previously examined by Tebartz Van Elst and colleagues; ${ }^{15}$ VBM based on SPM99 was used to assess for morphometric differences and no significant cortical grey matter differences between the temporal lobe epilepsy with psychosis and the temporal lobe epilepsy only groups were found. However, the temporal lobe epilepsy only group showed a significant increase in grey matter concentration in the right temporal lobe relative to healthy controls. The authors concluded that since they observed no differences between temporal lobe epilepsy with psychosis and the temporal lobe epilepsy only groups, and since cortical pathology is prominent in schizophrenia, ${ }^{18}$ temporal lobe epilepsy with psychosis may represent a clinically distinct entity from schizophrenia.

In another VBM analysis, 20 people with temporal lobe epilepsy with psychosis were compared with 20 participants with temporal lobe epilepsy without psychosis where they were matched with respect to conventional MRI findings. ${ }^{50}$ Global and hippocampal volumes were assessed. No significant differences were found between those with and without psychosis but significant reductions of magnetisation transfer ratio (an index of signal loss derived from magnetisation transfer imaging) in the absence of atrophy was found in the left superior and middle temporal gyri in participants with psychosis.

Our finding of cortical grey matter abnormalities are in keeping with those of Flugel and colleagues ${ }^{50}$ but contrast with those of Rusch et al. ${ }^{17}$ Although our sample size was smaller than that of Rusch et al (26 v. 10 with temporal lobe epilepsy with psychosis), the participants in our study were more tightly 


\begin{tabular}{|c|c|c|c|c|c|}
\hline \multirow[b]{2}{*}{ Cluster size: voxels, $n$} & \multicolumn{3}{|c|}{ Talairach and Tournoux coordinates } & \multirow[b]{2}{*}{ Region } & \multirow[b]{2}{*}{ Hemisphere } \\
\hline & $x$ & $y$ & $z$ & & \\
\hline \multicolumn{6}{|l|}{1770} \\
\hline & -25 & -6 & -33 & Inferior temporal gyrus & Left \\
\hline & -40 & -65 & -27 & Posterior lobe of cerebellum & Left \\
\hline & -21 & -10 & -20 & Parahippocampal gyrus & Left \\
\hline & -37 & -34 & -15 & Fusiform gyrus & Left \\
\hline & -39 & -3 & -13 & Hippocampus & Left \\
\hline & -56 & -17 & -9 & Middle temporal gyrus & Left \\
\hline \multicolumn{6}{|l|}{475} \\
\hline & 49 & -13 & -33 & Inferior temporal gyrus & Right \\
\hline & 44 & -30 & -21 & Fusiform gyrus & Right \\
\hline & 41 & 1 & -14 & Superior temporal gyrus & Right \\
\hline & 52 & 12 & 8 & Superior temporal gyrus & Right \\
\hline \multicolumn{6}{|l|}{354} \\
\hline & 2 & 2 & -10 & Anterior cingulum & Right \\
\hline & 1 & -1 & 1 & Caudate & Right \\
\hline & -9 & 6 & 14 & Caudate & Left \\
\hline \multicolumn{6}{|l|}{597} \\
\hline & -43 & -16 & 10 & Insula & Left \\
\hline & -52 & -33 & 24 & Inferior parietal lobule & Left \\
\hline \multicolumn{6}{|l|}{632} \\
\hline & 43 & -12 & -6 & Insula & Right \\
\hline & 39 & -19 & 19 & Insula & Right \\
\hline
\end{tabular}

\begin{tabular}{|c|c|c|c|c|c|}
\hline \multirow[b]{2}{*}{ Cluster size: voxels, $n$} & \multicolumn{3}{|c|}{ Talairach and Tournoux coordinates } & \multirow[b]{2}{*}{ Region } & \multirow[b]{2}{*}{ Hemisphere } \\
\hline & $x$ & $y$ & $z$ & & \\
\hline \multirow[t]{12}{*}{1733} & -41 & -8 & -27 & Fusiform gyrus & Left \\
\hline & -36 & -6 & -23 & Inferior temporal gyrus & Left \\
\hline & -36 & -8 & -20 & Parahippocampal gyrus & Left \\
\hline & -36 & -18 & -13 & Hippocampus & Left \\
\hline & -44 & -7 & -10 & Middle temporal gyrus & Left \\
\hline & -29 & -50 & 3 & Lingual gyrus & Left \\
\hline & -13 & 16 & 3 & Anterior limb of internal capsule & Left \\
\hline & -33 & -43 & 6 & Posterior thalamic radiation & Left \\
\hline & -14 & 22 & 8 & Genu of corpus callosum & Left \\
\hline & -14 & 16 & 10 & Caudate & Left \\
\hline & -21 & -41 & 17 & Splenium of corpus callosum & Left \\
\hline & -14 & -15 & 27 & Cingulum & Left \\
\hline \multicolumn{6}{|l|}{1106} \\
\hline & 35 & -4 & -23 & Inferior temporal gyrus & Right \\
\hline & 49 & -24 & -16 & Fusiform gyrus & Right \\
\hline & 14 & -15 & -13 & Midbrain & Right \\
\hline & 32 & -16 & -9 & Hippocampus & Right \\
\hline & 31 & -18 & -6 & Parahippocampal gyrus & Right \\
\hline & 41 & -27 & 2 & Posterior thalamic radiation & Right \\
\hline & 45 & -27 & 5 & Superior temporal gyrus & Right \\
\hline & 22 & 18 & 6 & Anterior limb of internal capsule & Right \\
\hline & 21 & 20 & 14 & Genu of corpus callosum & Right \\
\hline & 28 & -36 & 20 & Splenium of corpus callosum & Right \\
\hline & 18 & -1 & 26 & Cingulum & Right \\
\hline
\end{tabular}

matched for psychiatric disorder and handedness. Furthermore, Rusch and colleagues utilised a neuroimaging protocol involving a brain template derived from healthy participants. Given that individual variability of brains in the study population is substantially increased by injury or disease, achieving satisfactory alignment across individual brains may have resulted in registration difficulties. Additionally, we report widespread grey and white matter changes not confined to the temporal lobes where our findings may contrast with previous automated statistical methods as our approach utilised instead unified segmentation that combined tissue classification, bias correction and non-linear warping within the same framework ${ }^{31}$ and our 
non-parametric or distribution-free hypothesis testing procedure permits us to use cluster-level statistics even if their distribution is non-Gaussian (even after smoothing).

\section{Limitations}

There are other methodological considerations and limitations to our study. We only used MRI data-sets from 2002 onwards so as to ensure homogeneity of scans while applying strict exclusion criteria for recruitment into the study; although this may have limited the number of participants and affected the power of our study, there are several other studies that have applied VBM in schizophrenia where significant differences in grey and white matter have been reported using similar sample sizes. ${ }^{51,52}$ Therefore it is unlikely that type I error fully accounts for our findings.

The clinical psychiatric diagnoses that were obtained through neuropsychiatric assessment were not achieved through formal structured clinical interviews but they contained comprehensive clinical information that could be retrospectively evaluated through OPCRIT. Future studies investigating temporal lobe epilepsy with psychosis may wish to consider a methodological design that prospectively examines individuals with temporal lobe epilepsy through structured clinical interviews, for example the Structured Clinical Interview for DSM-IV, ${ }^{53}$ and further, to utilise objective rating scales for psychosis, for example the Brief Psychiatric Rating Scale ${ }^{54}$ or the Positive and Negative Syndrome Scale. ${ }^{55}$ However, to recruit reasonable numbers prospectively would take many years; despite our retrospective recruitment, finding appropriate participants once exclusion criteria have been applied (surgery, tumours, etc.) left us with ten participants in a 4-year period; thus recruitment is a problem in the study of temporal lobe epilepsy with psychosis.

Moreover, in a recent study, although widespread neocortical abnormalities were found in both temporal lobe epilepsy with and without mesial sclerosis, the pattern of thinning in the former contrasted with the latter; which led the authors to suggest that these might constitute two distinct temporal lobe epilepsy syndromes. ${ }^{56}$ Future studies may wish to separately characterise the neurobiology of these disorders. Similarly, the assessment of post-ictal and inter-ictal forms of psychoses related to temporal lobe epilepsy should perhaps be investigated separately in future studies. However, when these factors are taken together, they may restrict further the overall number of study participants and given that it is not uncommon for the post-ictal form to progress to the inter-ictal variant, ${ }^{57}$ assessing both forms of psychoses in the same study represents a valid approach. ${ }^{17}$

We did not include normal controls in the study as we were primarily interested in the brain changes in temporal lobe epilepsy associated specifically with psychosis rather than the effects of epilepsy. Further, the absence of a control group is because this was a study based on an epilepsy patient database and therefore no individuals without epilepsy were recruited. However, the lack of a healthy control group limits the extent to which we can interpret our findings in the context of the general population. The current literature would suggest that people with temporal lobe epilepsy will have some regional volume loss compared with healthy controls, usually ipsilaterally and predominantly in temporal lobe regions. Undoubtedly, the recruitment of healthy controls poses an ongoing need and future studies at our centre should involve a healthy comparator group so as to enable meaningful differentiation of brain changes across both healthy and disease groups.

Tissue loss commonly affects disease groups, and tissue gain is less likely (apart from for instance a developmental disorder that might be accounted for by 'differential pruning'). In our study, however, clearly both groups are 'disease groups' with tissue loss most likely occurring in both. Even if the differences we are seeing are being driven by the non-psychosis group (i.e. grey matter increase), this still implies that these regions are somehow affected. It may also reflect that the psychosis group could be lacking a potential 'neuroprotective response' that is preventing the controls with temporal lobe epilepsy only from developing psychosis. Although this is one possibility, another is that SPM99 has been used in previous reports in temporal lobe epilepsy, whereas we have used SPM5 with better algorithms for tissue classification and bias correction. Indeed, Keller and colleagues ${ }^{20}$ suggest that the grey matter concentration excesses they found using SPM99 in their study reflects diminished grey-white matter demarcation, underlying white matter atrophy, or structural displacement as a result of cerebrospinal fluid expansion. This may also have accounted for an apparent increase in grey matter concentration in temporal lobe epilepsy relative to healthy controls in the report by Rusch and colleagues. ${ }^{17}$

\section{Implications}

Overall, our study recruited a population of people with temporal lobe epilepsy with strong diagnostic validity (both neurological and psychiatric) and through VBM, permitted an unbiased computerised statistical analysis of grey and white matter measures. The findings show that participants with temporal lobe epilepsy with psychosis have marked cortical, subcortical and extratemporal grey and white matter deficits compared with those with temporal lobe epilepsy alone and thus provide support for the psychosis literature that also shows this pattern of change. Our study has provided evidence allowing specific hypotheses to be tested in future studies, although recruitment of suitable individuals to investigate may prove to be an issue. Owing to such difficulties, it is important to conduct 'pilot' work such as ours to determine very specific hypotheses before attempts are made to recruit even larger cohorts.

\footnotetext{
Frederick Sundram, MB, MRCPsych, MA, Department of Psychiatry, Royal College of Surgeons in Ireland and Beaumont Hospital, Dublin, Ireland, and Department of Forensic and Neurodevelopmental Science, Institute of Psychiatry, King's College London, UK; Mary Cannon, MB, MSc, PhD, MRCPsych, Department of Psychiatry, Royal College of Surgeons in Ireland and Beaumont Hospital, Dublin, Ireland; Colin P. Doherty, MD, FRCPI, Department of Neurology, St James' Hospital, Dublin, Ireland; Gareth J. Barker, PhD, Department of Neuroimaging, Centre for Neuroimaging Sciences, Institute of Psychiatry, King's College London, UK Neuroimaging Sciences, Institute of Psychiatry, King's College London, UK;
Mary Fitzsimons, MSc, MBA, Department of Neurophysics, Brain Morphometry Laboratory, Beaumont Hospital, Dublin, Ireland; Norman Delanty, MB, FRCPI, ABPN (Dip), Department of Neurology, Beaumont Hospital, Dublin, Ireland; David Cotter, MB, MRCPsych, PhD, Department of Psychiatry, Royal College of Surgeons in Ireland and Beaumont Hospital, Dublin, Ireland

Correspondence: Frederick Sundram, Department of Psychiatry, Education and Research Centre, Royal College of Surgeons in Ireland, Beaumont Hospital, Dublin 9, Ireland. Email: fsundram@rcsi.ie

First received 18 Mar 2010, final revision 10 July 2010, accepted 22 Jul 2010
}

\section{Funding}

M.C. was funded by a Clinician Scientist Award (CSA/2004/1) from the Health Research Board (Ireland) and an Essel Foundation Independent Investigator award from NARSAD (USA).

\section{Acknowledgements}

We thank all those who participated in this study. We are grateful to the radiographers at the Beaumont Hospital MRI scanner for their help at scanning sessions. 


\section{References}

1 MacDonald BK, Cockerell OC, Sander JW, Shorvon SD. The incidence and lifetime prevalence of neurological disorders in a prospective communitybased study in the UK. Brain 2000; 123: 665-76.

2 Swinkels WA, Kuyk J, van Dyck R, Spinhoven P. Psychiatric comorbidity in epilepsy. Epilepsy Behav 2005; 7: 37-50.

3 Kendler KS, Gallagher TJ, Abelson JM, Kessler RC. Lifetime prevalence, demographic risk factors, and diagnostic validity of nonaffective psychosis as assessed in a US community sample. The National Comorbidity Survey. Arch Gen Psychiatry 1996; 53: 1022-31.

4 Mendez MF, Grau R, Doss RC, Taylor JL. Schizophrenia in epilepsy: seizure and psychosis variables. Neurology 1993; 43: 1073-7.

5 Bredkjaer SR, Mortensen PB, Parnas J. Epilepsy and non-organic nonaffective psychosis. National epidemiologic study. Br J Psychiatry 1998; 172 235-8.

6 Gaitatzis A, Trimble MR, Sander JW. The psychiatric comorbidity of epilepsy Acta Neurol Scand 2004; 110: 207-20.

7 Torta R, Keller R. Behavioral, psychotic, and anxiety disorders in epilepsy: etiology, clinical features, and therapeutic implications. Epilepsia 1999; 40 (suppl 10): S2-20.

8 Slater E, Beard AW. The schizophrenia-like psychoses of epilepsy. i. Psychiatric aspects. Br J Psychiatry 1963; 109: 95-150.

9 Flor-Henry P. Psychosis and temporal lobe epilepsy. A controlled investigation. Epilepsia 1969; 10: 363-95.

10 Roberts GW, Done DJ, Bruton C, Crow TJ. A 'mock up' of schizophrenia: temporal lobe epilepsy and schizophrenia-like psychosis. Biol Psychiatry 1990; 28: 127-43.

11 Qin $\mathrm{P}, \mathrm{Xu} \mathrm{H}$, Laursen TM, Vestergaard M, Mortensen PB. Risk for schizophrenia and schizophrenia-like psychosis among patients with epilepsy: population based cohort study. Br Med J (Clinical Res Ed) 2005; 331: 23.

12 Adachi N, Akanuma N, Ito M, Kato M, Hara T, Oana Y, et al. Epileptic, organic and genetic vulnerabilities for timing of the development of interictal psychosis. Br J Psychiatry 2010; 196: 212-6.

13 Lewis DV. Losing neurons: selective vulnerability and mesial temporal sclerosis. Epilepsia 2005; 46 (suppl 7): 39-44.

14 Marsh L, Sullivan EV, Morrell M, Lim KO, Pfefferbaum A. Structural brain abnormalities in patients with schizophrenia, epilepsy, and epilepsy with chronic interictal psychosis. Psychiatry Res 2001; 108: 1-15.

15 Tebartz Van Elst L, Baeumer D, Lemieux L, Woermann FG, Koepp M, Krishnamoorthy $S$, et al. Amygdala pathology in psychosis of epilepsy: a magnetic resonance imaging study in patients with temporal lobe epilepsy. Brain 2002; 125: 140-9.

16 Marchetti RL, Azevedo Jr D, de Campos Bottino CM, Kurcgant D, de Fatima Horvath Marques A, Marie SK, et al. Volumetric evidence of a left laterality effect in epileptic psychosis. Epilepsy Behav 2003; 4: 234-40.

17 Rusch N, Tebartz van Elst L, Baeumer D, Ebert D, Trimble MR. Absence of cortical gray matter abnormalities in psychosis of epilepsy: a voxel-based MRI study in patients with temporal lobe epilepsy. J Neuropsychiatry Clin Neurosci 2004; 16: 148-55.

18 Wright IC, Rabe-Hesketh S, Woodruff PW, David AS, Murray RM, Bullmore ET Meta-analysis of regional brain volumes in schizophrenia. Am J Psychiatry 2000; 157: 16-25.

19 Gur RE, Keshavan MS, Lawrie SM. Deconstructing psychosis with human brain imaging. Schizophr Bull 2007; 33: 921-31.

20 Keller SS, Mackay CE, Barrick TR, Wieshmann UC, Howard MA, Roberts N. Voxel-based morphometric comparison of hippocampal and extrahippocampal abnormalities in patients with left and right hippocampal atrophy. Neurolmage 2002; 16: 23-31

21 Proposal for revised classification of epilepsies and epileptic syndromes. Commission on Classification and Terminology of the International League Against Epilepsy. Epilepsia 1989; 30: 389-99.

22 Ronan L, Doherty CP, Delanty N, Thornton J, Fitzsimons M. Quantitative MRI: a reliable protocol for measurement of cerebral gyrification using stereology Magn Reson Imaging 2006; 24: 265-72.

23 Kinirons P, Cavalleri GL, Shahwan A, Wood NW, Goldstein DB, Sisodiya SM, et al. Examining the role of common genetic variation in the gamma2 subunit of the GABA(A) receptor in epilepsy using tagging SNPs. Epilepsy Res 2006; 70: 229-38.

24 Ronan L, Murphy K, Delanty N, Doherty C, Maguire S, Scanlon C, et al. Cerebral cortical gyrification: a preliminary investigation in temporal lobe epilepsy. Epilepsia 2007; 48: 211-9.
25 World Health Organization. The ICD-10 Classification of Mental and Behavioural Disorders: Clinical Descriptions and Diagnostic Guidelines. WHO, 1992.

26 Wechsler D. WAIS-R: Manual: Wechsler Adult Intelligence Scale - Revised. The Psychological Corporation, 1981.

27 McGuffin P, Farmer A, Harvey I. A polydiagnostic application of operational criteria in studies of psychotic illness. Development and reliability of the OPCRIT system. Arch Gen Psychiatry 1991; 48: 764-70.

28 Williams J, Farmer AE, Ackenheil M, Kaufmann CA, McGuffin P. A multicentre inter-rater reliability study using the OPCRIT computerized diagnostic system. Psychol Med 1996; 26: 775-83.

29 Ashburner J, Friston KJ. Voxel-based morphometry - the methods. Neurolmage 2000; 11: 805-21.

30 Good CD, Johnsrude IS, Ashburner J, Henson RN, Friston KJ, Frackowiak RS A voxel-based morphometric study of ageing in 465 normal adult human brains. Neurolmage 2001; 14: 21-36.

31 Ashburner J, Friston KJ. Unified segmentation. Neurolmage 2005; 26: 839-51.

32 Keller SS, Roberts N. Voxel-based morphometry of temporal lobe epilepsy: an introduction and review of the literature. Epilepsia 2008; 49: 741-57.

33 Mechelli A, Friston KJ, Frackowiak RS, Price CJ. Structural covariance in the human cortex. J Neurosci 2005; 25: 8303-10.

34 Bullmore ET, Suckling J, Overmeyer S, Rabe-Hesketh S, Taylor E, Brammer MJ. Global, voxel, and cluster tests, by theory and permutation, for a difference between two groups of structural MR images of the brain. IEEE Trans Med Imaging 1999; 18: 32-42.

35 Shapleske J, Rossell SL, Chitnis XA, Suckling J, Simmons A, Bullmore ET, et al. A computational morphometric MRI study of schizophrenia: effects of hallucinations. Cereb Cortex 2002; 12: 1331-41.

36 Brett M, Johnsrude IS, Owen AM. The problem of functional localization in the human brain. Nature Rev 2002; 3: 243-9.

37 Talairach J, Tournoux P. Co-planar Stereotaxic Atlas of the Human Brain. Thieme, 1988.

38 Rabe-Hesketh S, Bullmore ET, Brammer MJ. The analysis of functional magnetic resonance images. Stat Methods Med Res 1997; 6: 215-37.

39 Poline JB, Mazoyer BM. Analysis of individual positron emission tomography activation maps by detection of high signal-to-noise-ratio pixel clusters. J Cereb Blood Flow Metab 1993; 13: 425-37.

40 Pantelis C, Velakoulis D, McGorry PD, Wood SJ, Suckling J, Phillips LJ, et al. Neuroanatomical abnormalities before and after onset of psychosis: a crosssectional and longitudinal MRI comparison. Lancet 2003; 361: 281-8.

41 Seidman LJ, Pantelis C, Keshavan MS, Faraone SV, Goldstein JM, Horton NJ, et al. A review and new report of medial temporal lobe dysfunction as a vulnerability indicator for schizophrenia: a magnetic resonance imaging morphometric family study of the parahippocampal gyrus. Schizophr Bull 2003; 29: 803-30

42 Andreasen NC, Paradiso S, O'Leary DS. 'Cognitive dysmetria' as an integrative theory of schizophrenia: a dysfunction in cortical-subcorticalcerebellar circuitry? Schizophr Bull 1998; 24: 203-18.

43 Sandok EK, O'Brien TJ, Jack CR, So EL. Significance of cerebellar atrophy in intractable temporal lobe epilepsy: a quantitative MRI study. Epilepsia 2000; 41: 1315-20.

44 Andreasen NC, Pierson R. The role of the cerebellum in schizophrenia. Biol Psychiatry 2008; 64: 81-8.

45 Hoffman RE, McGlashan TH. Reduced corticocortical connectivity can induce speech perception pathology and hallucinated 'voices'. Schizophr Res 1998; 30: $137-41$.

46 Brambilla $\mathrm{P}$, Tansella $\mathrm{M}$. The role of white matter for the pathophysiology of schizophrenia. Int Rev Psychiatry 2007; 19: 459-68.

47 Sundram F, Campbell LE, Azuma R, Daly E, Bloemen OJN, Barker GJ, et al. White matter microstructure in 22q11 deletion syndrome: a pilot diffusion tensor imaging and voxel-based morphometry study of children and adolescents. J Neurodevelop Disord 2010; 2: 77-92.

48 Currie S, Heathfield KW, Henson RA, Scott DF. Clinical course and prognosis of temporal lobe epilepsy. A survey of 666 patients. Brain 1971; 94: 173-90.

49 Sachdev P. Schizophrenia-like psychosis and epilepsy: the status of the association. Am J Psychiatry 1998; 155: 325-36.

50 Flugel D, Cercignani M, Symms MR, Koepp MJ, Foong J. A magnetization transfer imaging study in patients with temporal lobe epilepsy and interictal psychosis. Biol Psychiatry 2006; 59: 560-7.

51 Sowell ER, Levitt J, Thompson PM, Holmes CJ, Blanton RE, Kornsand DS, et al. Brain abnormalities in early-onset schizophrenia spectrum disorder observed with statistical parametric mapping of structural magnetic resonance images. Am J Psychiatry 2000; 157: 1475-84. 
52 Kubicki M, Shenton ME, Salisbury DF, Hirayasu $Y$, Kasai K, Kikinis R, et al. Voxel-based morphometric analysis of gray matter in first episode schizophrenia. Neurolmage 2002; 17: 1711-9.

53 First MB, Gibbon M, Spitzer RL, Williams JBW, Benjamin LS. Structured Clinical Interview for DSM-IV-TR Axis I Disorders, Research Version, Patient Edition $(S C I D-I / P)$. American Psychiatric Press, 1997.

54 Kay SR, Fiszbein A, Opler LA. The positive and negative syndrome scale (PANSS) for schizophrenia. Schizophr Bull 1987; 13: 261-76.
55 Overall JE, Gorham DR. The Brief Psychiatric Rating Scale. Psychol Rep 1962; 10: $799-812$.

56 Mueller SG, Laxer KD, Barakos J, Cheong I, Garcia P, Weiner MW. Widespread neocortical abnormalities in temporal lobe epilepsy with and without mesial sclerosis. Neurolmage 2009; 46: 353-9.

57 Tarulli A, Devinsky O, Alper K. Progression of postictal to interictal psychosis. Epilepsia 2001; 42: 1468-71.

\section{psychiatry in the Old
Testament in the old
Testament}

\section{Hannah: a case of infertility and depression}

\section{George Stein}

Childlessness was a tragedy for a woman in the ancient near East and the barren wife was likely to be despised by her husband, family and society at large. In the Old Testament, three childless women are described whose infertility was relieved by divine intervention, resulting in the birth of important patriarchal leaders.

Sarah, the mother of Isaac, was 90 years old when she heard she was to have a baby.

Gen. 18:13 'And the Lord said to Abraham, why did Sarah laugh and say shall I indeed bear a child now that I am old'.

The only other recorded emotional reaction Sarah has to her infertility is that she was harsh to Hagai, Abraham's other wife and the mother of Ishmael - 'then Sarah dealt harshly with her (Hagai) and she ran away from her'.

We know even less about the infertility of the mother of Samson. Her story is described in the book of Judges and she is known only as the wife of Manoah.

Judg. 13:13 'And the angel of the Lord appeared to the woman and said to her "although you are barren, having no children you shall conceive and bear a son." ' In due course she gave birth to Samson. Her existence in the Bible relates solely to her maternal function and the text says nothing about her personal feelings, her relationships, or even her name as she is identified only through her husband, as 'the wife of Manoah'.

The third woman, Hannah, is also childless but eventually gives birth to another important biblical prophet, Samuel. However, her story is very different from the other two women's stories and the Bible gives a very personal account of her feelings, her sadness at the infertility, her relationship with her husband, Elkanah, the difficulties and envy of living with Elkanah's other wife, Peninnah, who did have children, as well as her misery, described in sufficient detail to make a diagnosis of depression likely.

1 Sam. 1.2 ' He (Elkanah) had two wives: the name of one Hannah, and the name of the other Peninnah. Peninnah had children, but Hannah had none .. 1:6 her rival (Penninah) used to provoke her severely, to irritate her because the Lord had closed her womb. 7 Therefore Hannah wept and would not eat. 8 Her husband said to her 'Hannah why do you weep? Why do you not eat? Why is your heart so sad? ... 10 She was deeply distressed and prayed to the Lord and wept bitterly. 11 She made this vow "Oh Lord of hosts, if only you will look on the misery of your servant and remember me and not forget your servant but will give to your servant a male child then I will set him before you as a Nazirite until the day of his death." 12 As she continued praying before the Lord, Eli (the priest) observed her mouth. 13 Hannah was praying silently, but her voice was not heard; therefore Eli thought she was drunk. 14 So Eli said to her "How long will you make a drunken spectacle of yourself." But Hannah answered "No my Lord, I am a woman deeply troubled, I have drunk neither wine nor strong drink, but I have been pouring out my soul before the Lord. 16 Do not regard your servant as a worthless woman, for I have been speaking out of my great anxiety and vexation all the time." 17 Then Eli answered "Go in Peace; the God of Israel will grant the petition you have made to him" ... 18 Then the woman went to her quarters, ate and drank with her husband and her countenance was no longer sad ... 19 And then they went back to their house at Ramah. Elkanah knew his wife Hannah and the Lord remembered her. In due time Hannah conceived and bore a son. She named him Samuel for she said "I have asked him of the Lord".

In this account we learn of Hannah's great distress because of her infertility and a sufficient number of symptoms are mentioned to make a diagnosis of depression. Thus, Hannah is weeping, feels bitterness, misery and sadness, but after her prayer her countenance is no longer sad (possible depressive facies which is then relieved). Further, there is irritability, especially with Peninnah, loss of appetite, general distress, vexation and anxiety. There is also a curious loss of voice while she prays. This could be no more than silent prayer, but as she is mouthing the words, the high priest Eli believes her to be intoxicated. This picture is typical of aphonia, a hysterical conversion symptom commonly associated with depression.

The biblical feminist literature attributes great significance to Hannah's tale. It is the story of a woman with infertility and her psychological reactions, her relationships with her husband and God, her feelings towards her husband's other wife and the depression associated with her infertility. It stands in stark contrast to the earlier impersonal accounts of the childlessness of Sarah and the wife of Manoah where only their impaired maternal function is reported. Hannah's tale is also of great importance to psychiatry, particularly to the history of psychiatry. There are very few accounts of depression in the literature of the ancient world, and they appertain only to men, even though depression is more common in women. Hence it is likely that Hannah's story represents the first description of depression (and hysterical aphonia) in a woman.

Hannah is thought to have lived in the 11th century BCE, but the books of I and II Samuel were probably compiled sometime between the 7th and the 9th century BCE, more than two millennia before the more definitive accounts of depression written by Burton in the 17th century AD. Liaison psychiatry concerns the association between a psychiatric disorder and a general medical condition. Infertility is a recognised gynaecological disorder and so Hannah's tale represents the first recognisable case of liaison psychiatry. 